\title{
Entrevista: Marcus Rediker
}

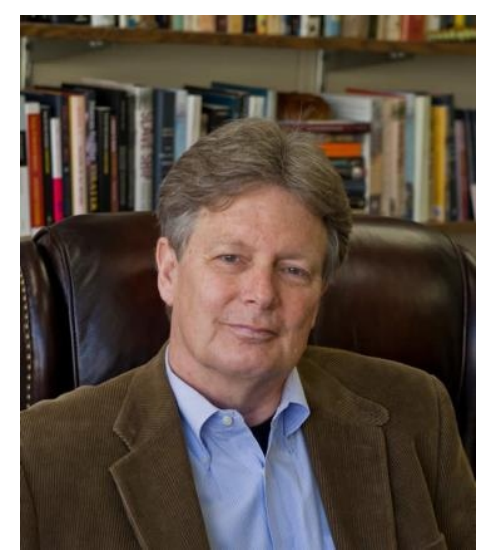

O professor Marcus Rediker nasceu em Owensboro, Kentucky, em 1951. Graduou-se com um B. A. na Virginia Commonwealth University, em 1976. Ele foi para a Universidade da Pensilvânia para o estudo de pósgraduação, obtendo um M.A. e Ph.D. em História. Ele ensinou na Universidade de Georgetown entre 1982 e 1994, viveu em Moscou por um ano (1984-5), e atualmente é Professor e Presidente do Departamento de História da Universidade de Pittsburgh. Ele escreveu (ou co-escreveu) nove livros: Between the Devil and the Deep Blue Sea (1987), Who Built America? (1989), volume um; A Hidra de muitas cabeças (2000), Villains of All Nations (2004), The Slave Ship: A Human History (2007), Many Middle Passages (2007), The Amistad Rebellion (2012), Mutiny and Maritime Radicalism in the Age of Revolution (2013) and Outlaws of the Atlantic (2014). Atualmente ele está escrevendo sobre a vida e os tempos do abolicionista radical Benjamin Lay (1682-1759). Esta entrevista discute os principais pontos de sua obra.

Hydra: Saudações Professor Rediker. É um grande prazer tê-lo conosco na primeira edição da Hydra. Falando de Hydra, 15 anos se passaram desde que você e o Professor Peter Linebaugh publicaram, pela primeira vez, o livro A Hidra de muitas cabeças: marinheiros, escravos, plebeus, e a história oculta Atlântico Revolucionário, lançado aqui no Brasil em 2008. Como você vê a repercussão historiográfica deste trabalho em várias partes do mundo? Existe alguma crítica ao livro que você gostaria de abordar, em particular? Considerando o tempo decorrido de publicação, existem desenvolvimentos em sua pesquisa que lançariam uma nova luz sobre o livro? 
Marcus Rediker: Antes de tudo, deixem-me saudar os editores e leitores da Revista Hydra e dizer o quão satisfeito estou em relação à formação desta revista. É uma honra ela ter retirado o seu nome do livro que vocês mencionam, a Hidra de muitas cabeças, que Peter Linebaugh e eu originalmente publicamos em 2000. Estamos muito satisfeitos que o livro tenha amigos no Brasil. Hydra teve uma vida rica ao longo dos últimos quinze anos. Ele já apareceu em edições em Inglês, Francês, Alemão, Italiano, Coreano, Português, e Espanhol, e entendo que uma tradução para o Japonês está bem encaminhada. Foi o texto fundador do Grupo de História Radical de Bristol (Reino Unido), uma associação vibrante, baseada na comunidade, que trouxe a história vista de baixo para mais perto da vida das pessoas, sobretudo por meio da sua livraria, Hydra Livros! O livro teve um impacto na África do Sul, entre pesquisadores e ativistas, e na Índia, onde uma edição "pirata" circulou através da Universidade Jawaharlal Nehru em Nova Deli. Ele encontrou ressonância na Austrália, no Caribe e na América Latina, especialmente no Brasil, Colômbia, Cuba e Costa Rica. Ele inspirou e influenciou a arte dramática ("The Delivery and the Patience" de Mike Nelson e a "Hydra Decapita" do grupo Otolith), música (do folk ao eletrônico ao punk), ficção (Sea of Poppies do Amitav Ghosh entre outros romances) e drama ("Belize” de Paulo Zimet e "1741" de John F. Levin). Ele antecipou e ajudou a avançar uma nova e importante tendência no conhecimento histórico ao longo da última década: a virada da história nacional para a história transnacional, oceânica, e global. Ele também tem desempenhado um papel em vários movimentos de baixo, que vão desde movimentos anti-globalização a campanha contra a pena de morte, à luta para recuperar os bens comuns, o Occupy. O artístico e o político se reuniram em uma exposição chamada "Hydrarchy" (o título do quinto capítulo do livro), que estreou em Londres em 2010 e no Cairo em 2012.

A minha crítica favorita é a seguinte: foi dito que o livro, que estudou milhões de pessoas através de uma vasta extensão do espaço geográfico num período de dois séculos e meio, não fez o suficiente! Nós fizemos o melhor que podíamos tendo em vista o nosso tempo e treinamento e agora cabe a outros estudiosos - no Brasil, por exemplo - expandir os temas, espaço e cronologia da história transnacional, e de fato isso está acontecendo. Um dos nossos objetivos era ajudar a abrir um novo tipo de 
história vista de baixo, além das fronteiras do Estado-nação, para uma investigação mais ampla e profunda. Eu acho que nós alcançamos este resultado.

Hydra: Outro trabalho seu que teve grande impacto no Brasil é The Slave Ship: A Human History (2007), no qual você utiliza vasta evidência documental principalmente escrita em primeira pessoa, como memórias e autobiografias - para narrar a história do tráfico de escravos do ponto de vista das pessoas que vivenciaram a experiência. Desde então, temos visto, aqui, um interesse crescente em reiterar ou compor uma "história vista de baixo" dos escravizados. O senhor poderia comentar sobre a contribuição desta abordagem para as obras académicas relacionadas com o Atlântico Sul? Existe algum desse trabalho sobre o assunto, portanto, que você gostaria de destacar?

Marcus Rediker: O trabalho histórico sobre a escravidão por estudiosos brasileiros está entre os melhores e mais sofisticados a serem encontrados em qualquer lugar do mundo. Aprecio, em especial, os estudos históricos de João José Reis, Ana Lúcia Araújo, e Luiz Felipe de Alencastro.

Hydra: Após a recepção e discussão do seu trabalho no Brasil, uma crítica veio à tona alegando que você ainda estava muito guiado pela história do Atlântico Norte, utilizando o Atlântico Sul só para complexificar as interpretações de sua própria área de interesse, o Atlântico Norte. Essas críticas têm influenciado suas obras posteriores? Como você avalia as análises recentes que lidam com as relações entre o Atlântico Norte e Atlântico Sul, bem como as perspectivas globais e transnacionais?

Marcus Rediker: É certamente verdade que a ênfase anglófona de Hydra foi uma limitação do trabalho e, claro, a dinâmica da discussão pautou meu trabalho futuro. Meu movimento principal não foi para o sul, mas sim para o leste, em direção à África. Originalmente formado como especialista em história americana colonial, estudei a África Ocidental intensivamente para os meus livros posteriores, The Slave Ship (2007) e The Amistad Rebellion (2012). 
Precisamos estudar historicamente circuitos específicos de trabalho e acumulação de capital, quer seja Londres-Gold Coast-Jamaica, Nantes-Senegal-Santo Domingo, ou Lisboa-Angola-Salvador. E, eventualmente, precisamos colocar estes vários circuitos em conjunto para ver como todo o sistema ou o capitalismo Atlântico funcionou de fato. Essa é a grande tarefa diante de nós.

Hydra: Você pode comentar sobre o processo de pesquisa que resultou em seu trabalho The Amistad Rebellion: An Atlantic Odyssey of Slavery and Freedom (2012)? Como foi retomar um tema que, por um lado, tem alguma dificuldade em termos de evidências documentais (como rebeliões no mar) e, por outro, já é bem conhecido pelo público a partir de representações enraizadas (como o filme de Spielberg)? Você poderia falar com mais vagar sobre o processo de produção do documentário que se originou a partir desta pesquisa, e das possibilidades trazidas pela produção audiovisual para o trabalho do historiador?

Marcus Rediker: The Amistad Rebellion foi um desafio porque eu avancei significativamente no tempo, ao século XIX, e porque os historiadores experientes me avisaram que não iria descobrir algo novo. Mas eu gosto de desafios, então eu segui em frente. Descobri que havia uma enorme quantidade de evidências disponíveis sobre o lado africano da história, algumas delas em fontes que muitos outros estudiosos já haviam consultado. Eles tinham ignorado esta parte crucial da história porque, como Spielberg, estavam focados no drama de tribunal (especialmente nos atores brancos, de elite, no caso), em vez da revolta, do drama a bordo, e dos africanos que fizeram isso acontecer.

Gosto de ensinar contra o filme de Spielberg. Ele representa a história vista de cima de uma forma clara e muitas vezes atraente. É fácil pedir às pessoas para ver toda a história do ponto de vista dos africanos escravizados. De algumas maneiras, o filme de Spielberg tornou o meu trabalho mais fácil.

Então eu decidi criar um filme de minha autoria, Ghosts of Amistad: In the Footsteps of the Rebels, que narra uma viagem para a Serra Leoa em 2013 para visitar as aldeias 
de origem das pessoas que tomaram o Amistad em 1839, para entrevistar os anciães sobre a memória local do caso, e para procurar as ruínas há muito perdidos de Lomboko, a fábrica de comércio de escravos onde começou a cruel viagem transatlântica. Eu trabalhei com o diretor Tony Buba, conhecido por seu trabalho em "filmes sobre a classe trabalhadora". Uma conversa entre Tony e eu, intitulada "Cinema visto de baixo encontra a história vista de baixo" pode ser encontrada aqui:

http://www.ghostsofamistad.com/about/from-the-directors-and-producers/

Foi uma experiência fascinante trabalhar com Tony em um novo meio. Eu acho que os historiadores deveriam explorar todas as formas possíveis de apresentar seu trabalho para o maior público possível. Para este mesmo fim eu também tenho trabalhado, ao longo do ano passado, com os dramaturgos Naomi Wallace e Randy Sharp, ambos os quais têm escrito peças inspiradas em The Slave Ship.

Hydra: Em seu livro mais recente Outlaws of the Atlantic, você demonstra a importância do papel dos "fora da lei" para a construção do mundo marítimo na modernidade. Como você vê a perspectiva de liberdade dos escravizados em relação à construção do proletariado e os chamados "lúmpen" (underclass)?

Marcus Rediker: Eu não gosto do conceito de "lúmpen" (underclass) - em vez disso talvez devêssemos falar sobre o problema da classe dirigente (overclass) - mas eu gosto de tudo o mais sobre a questão.

Este livro é uma coleção de palestras e ensaios abrangendo as últimas três décadas, organizados em torno do tema do espaço marítimo, que normalmente consideramos como o espaço irreal entre os lugares "reais" - ou seja, em solo, nacionais. O meu ponto é não só que os processos históricos importantes, como formação de classes e raças aconteceu no mar, mas que os povos trabalhando ou viajando através dos mares exerciam suas agências dentro dessa história. Por exemplo, a palavra e o conceito de "atacar" (entrar em greve, "to strike") se originou quando os marinheiros "atacaram" 
as velas dos seus navios em uma disputa salarial em Londres em 1768. Seu trabalho coletivo no mar havia criado a solidariedade que lhes permitiu desenvolver uma nova arma nas lutas de trabalhadores em todo o mundo. A liberdade não foi dada do alto, mas sim criado a partir de baixo.

Hydra: Esta pergunta é sobre a escravidão moderna ou trabalho forçado. Há relatos de trabalho forçado de imigrantes latino-americanos no Brasil, bem como de outros trabalhadores em tais condições em outras partes do mundo. Como você vê essa questão, considerando este novo tipo de tráfico de seres humanos? Quais são os limites entre escravidão e liberdade hoje? Como você acha que um historiador pode olhar para esta questão sem cair em anacronismos? Levando em consideração a sua investigação sobre a dinâmica do tráfico de trabalhadores escravizados no Atlântico, gostaríamos de saber a sua perspectiva sobre este assunto.

Marcus Rediker: É verdade, como Kevin Bales tem argumentando há muito, que o trabalho escravo, de uma forma ou de outra, é generalizado na economia capitalista global. Estima-se que trinta milhões de pessoas, muitas delas no Brasil, estão vinculadas a seus postos de trabalho pela ameaça ou realidade da violência. Este número representa mais "escravos" do que aqueles que existiam no auge do sistema de escravos do Atlântico do século XIX, embora também deva ser salientado que estes trabalhadores não-livres contemporâneos compõem uma menor percentagem da população do mundo do que os seus antepassados do século XIX . Ainda assim, a narrativa liberal de que um dia, há muito tempo, todas as pessoas boas puseram um fim à escravidão é claramente falso, porque o que realmente aconteceu em muitos casos foi que a forma de exploração mudou - da escravidão para a parceria rural na América do Sul, por exemplo. A opressão racial/de classe permaneceu mais ou menos constante.

Devo acrescentar que eu sou crítico de como alguns "abolicionistas" contemporâneos brincam livremente com a definição de escravidão e não respeitam adequadamente a história da instituição. Tendo isto em vista, eu tenho trabalhado com um grupo 
chamado 'Os historiadores contra a escravidão' cujo objetivo é tornar disponível, para os ativistas, o melhor conhecimento e sabedoria histórica aos que desejam se opor e, eventualmente, abolir o trabalho escravo.

Hydra: Em sua página oficial da web você se define como um "historiador, escritor e ativista". Você também participa do movimento global para a abolição da pena de morte. Como você vê a relação entre essas várias formas de ação e de intervenção? E qual é o papel do "ativista" para o ofício do historiador?

Conhecimento acadêmico e ativismo podem se enriquecer mutuamente. Aqui está um exemplo pessoal: na década de 1990, enquanto Peter Linebaugh e eu estávamos trabalhando em Hydra, eu estava envolvido na campanha de defesa legal de Mumia Abu-Jamal, um ex-Pantera Negra que estava no corredor da morte depois de ter sido falsamente condenado, em 1982, por matar um policial na Filadélfia.

Visitei Mumia regularmente em sua prisão de segurança super-máxima SCI-Green, em Waynesburg, Pensilvânia. Eu aprendi sobre prisões e pena capital, e em um nível mais abstrato sobre raça e terror, e fui sensibilizado para a importância destas práticas e conceitos na longa história do capitalismo. Os temas de Hidra refletem essa experiência de aprendizagem.

Envolvimento em movimentos de baixo pode ensinar aos historiadores como a história funciona e como ação radical moldou o passado e o presente. Mas antes que possamos entender estas coisas, devemos aprender a ouvir - isto é, aprender a ouvir as vozes, em nossas fontes históricas, daqueles que sofreram opressão violenta. Assim como o nosso conhecimento das lutas passadas pode nos ajudar a tomar melhores decisões dentro dos movimentos de hoje, podemos expandir a nossa imaginação política e nossa visão sobre o passado ouvindo as pessoas envolvidas em lutas contemporâneas.

Finalmente, participar de movimentos a partir de baixo permite que um historiador teste as suas ideias sobre o passado. Os trabalhadores comuns dos movimentos de hoje acham as suas ideias úteis? Se sim, como? O que histórias de lutas passadas significam 
àqueles que lutam no presente? Fazer estas perguntas ajuda a nos manter honestos, ou seja, fundamentados na realidade.

Hydra: Professor, obrigado pela oportunidade e por inaugurar a seção de entrevistas da Hydra. Por último, gostaríamos de lhe pedir algumas palavras para a nova geração de historiadores que se vêem confrontados com um mundo no qual os sistemas de opressão e desigualdades sociais tornam-se cada vez mais devastadores. Qual é o nosso papel, como historiadores, no mundo de hoje?

Marcus Rediker: Meu conselho para todos os historiadores, e a todos os cidadãos, é: fale a verdade ao poder. Esta frase bíblica foi empregada por Quakers no século XVIII para enfatizar a responsabilidade que todas as pessoas têm de lutar contra a injustiça. Estou estudando agora um desses Quakers, um homem chamado Benjamin Lay, que foi uma das primeiras pessoas, em todo o mundo, a insistir que a escravidão deveria ser abolida, de imediato, sem recompensa aos proprietários de escravos. Ele estava dizendo isso em 1730, num período em que a escravidão era parte corriqueira do senso comum para a maioria das pessoas no mundo e muito antes de um movimento anti-escravidão ter surgido. Lay considerou que era sua obrigação moral se levantar contra a escravidão e insistir que era errada, ainda que tenha enfrentado uma feroz oposição ao dizê-lo. Ele demonstrou o poder de dizer não. Precisamos de histórias de muitas pessoas ao redor do mundo que disseram não à injustiça. Eles podem nos apontar para um futuro melhor. 